\title{
A rastreabilidade dos alimentos como política pública: exercício do direito à informação e o compromisso ético com o cumprimento das normas ambientais
}

The traceability of foods how to public policy: exercise of the right to information and ethical commitment with the fulfilment of environmental regulations

\section{Marcos Alexandre Alves ${ }^{1}$, Liziane Terezinha Machado Pereira ${ }^{2}$}

${ }^{1}$ Doutor em Educação, Curso de Filosofia e Programa de Pós-Graduação em Ensino de Ciências e Matemática, Centro Universitário Franciscano - UNIFRA, Santa Maria, RS, Brasil

${ }^{2}$ Bacharel de Direito, Advogada, Curso de Direito, Faculdade Palotina - FAPAS, Santa Maria, RS, Brasil

\begin{abstract}
Resumo
O artigo apresenta uma reflexão acerca da rastreabilidade dos alimentos como política pública e destaca, a partir do direito à informação, o compromisso ético-moral do consumidor-cidadão pelo cumprimento das normas ambientais. Utiliza-se de uma abordagem hermenêutica, no intuito de se interpretar a dinâmica que envolve os direitos/deveres do consumidor e o compromisso ético-ambiental de todos os cidadãos. $O$ acesso facilitado ao consumo, na sociedade contemporânea, acarretou danos ambientais, por isso se faz necessário a utilização de novas tecnologias para uma atuação pró-ativa do consumidor, a fim de se estabelecer um compromisso com o consumo consciente. Por fim, enfatizase que o princípio ético da responsabilidade do consumidor-cidadão, em suas escolhas, contribuirá para a manutenção e preservação de um meio ambiente sustentável.
\end{abstract}

Palavras-chave: Rastreabilidade alimentos; Direito do consumidor; Direito ambiental; Responsabilidade ética.

\begin{abstract}
The paper presents a reflection on the traceability of food as a public policy and highlights, from the right to information, the ethical and moral commitment of the consumer-citizen for compliance with environmental standards. It uses a hermeneutic approach, in order to interpret the dynamics involving the rights / obligations of the consumer and the ethical and environmental commitment of all citizens. The facilitated consumption in contemporary society, access caused environmental damage, so the use of new technologies for a pro-active role of the consumer in order to establish a commitment to conscious consumption is required. Finally, it is emphasized that the ethical principle that the consumer-citizen in your choices, contribute to maintaining and preserving a sustainable environment.
\end{abstract}




\section{Introdução}

O advento da Era Industrial, seguido da sociedade de consumo, trouxe severas consequências ambientais ao planeta, em decorrência da exploração desenfreada de recursos e inadequadas formas de sua utilização. Consumo e meio ambiente, conceitos que até o final do século XX eram vistos de forma dissociada, hoje devem ser entendidos como ramos de uma mesma árvore. A Constituição Federal, de 1988, trouxe a previsão da proteção ao consumidor e da proteção ao meio ambiente de maneira hierarquicamente igualitária. Na seara da produção de alimentos, verifica-se uma ampla produção legislativa que estabelecem exigências para uma produção que não agrida o meio ambiente e respeite a segurança e saúde alimentar dos consumidores.

Nesse sentido, a rastreabilidade dos alimentos representa a possibilidade de o consumidor-cidadão conhecer o histórico/origem dos produtos através de informações devidamente registradas. Todavia, questiona-se em que medida a implementação da rastreabilidade dos alimentos, como política pública, poderia contribuir para a efetividade no cumprimento, por parte do consumidor, das normas ambientais, a partir da possibilidade de exercício do direito à informação e seu correlato direito de escolha em adquirir produtos ambientalmente corretos.

Desse modo, em razão da importância do consumidor, em tempos de novas tecnologias e de acesso ao conhecimento, cumprir a sua tarefa ética-constitucional, de escolher conscientemente alimentos/produtos que respeitem as normas ambientais, desde o seu processo de produção até a entrega final. As novas tecnologias permitem inúmeras possibilidades de verificar a procedência dos alimentos, mediante o processo de rastreabilidade. Portanto, trata-se de um direito-dever do consumidor-cidadão saber a procedência dos alimentos que consome. $\mathrm{O}$ adequado exercício do direito à informação permitirá a contribuição do consumidor, para que não se perpetuem práticas de empresas ambientalmente inadequadas no mercado.

O objetivo do artigo é analisar a possibilidade de se implementar a rastreabilidade dos alimentos, como uma política pública, voltada ao consumidor e em prol do efetivo cumprimento das normas ambientais. Para tanto, faz-se necessária examinar a relação entre consumo consciente e meio ambiente sustentável, diante das fragilidades apresentadas pela sociedade de consumo. Bem como, mostrar que o direito do consumidor à informação, configura-se como compromisso ambiental do cidadão na estrutura do Estado Democrático de Direito, pois permite, através da rastreabilidade dos alimentos, a escolha consciente e ambientalmente correta do consumidor.

Para dar conta do objetivo proposto, empreendeu-se uma análise bibliográfica e utilizou-se de uma abordagem hermenêutica, no intuito de interpretar a dinâmica que envolve os direitos/deveres do consumidor e o compromisso ético-ambiental de todos os cidadãos. O acesso facilitado ao consumo, na sociedade contemporânea, acarretou danos ambientais, sendo imprescindível a utilização de novas tecnologias para a atuação pró-ativa do cidadão, no sentido de estabelecer uma responsabilidade ética pelo consumo sustentável. Nessa perspectiva, o direito à informação se constitui como um dos pressupostos para o cuidado ambiental e o consumo consciente, sobretudo, daqueles alimentos produzidos por empresas que respeitam os princípios éticos e as normas ambientais.

\section{Consumo sustentável: direito à informação e responsabilidade da escolha}

A sociedade contemporânea, pela sua característica consumerista, é protagonista de um verdadeiro processo de degradação ambiental, em escala mundial, que gradualmente coloca a vida do planeta em risco. Pode-se denominá-la como uma "sociedade de risco global" que nasce na época industrial e atinge o seu auge no período pós-industrial, pelos princípios básicos da economia de livre mercado, através de fenômenos como o crescimento de organizações globais e empresas multinacionais. O seu 
modelo de desenvolvimento é baseado na exploração de recursos naturais, nos avanços tecnológicos e nanotecnológicos, nas alterações das relações de trabalho, no capital financeiro volátil, no terrorismo, no crescimento do uso de energia nuclear, entre outros (ENGELMANN; BERGER FILHO, 2010).

Com efeito, a mudança de paradigma, em termos de cultura ocidental, com a troca do referencial religioso pelo referencial racional, fez com que as leis da natureza passassem a ser compreendidas a partir de uma lógica presumível, que comandaria a vida em suas múltiplas manifestações (CAVALCANTI, 2003). A partir disso, cria-se um estereótipo que consumir é saudável, e esse consumo com o avançar do século XIX para o século XX, torna-se desenfreado, posto que haja o consumo sem haver uma necessidade, tão somente para satisfazer o desejo.

Com fortes manifestações contrárias, iniciadas ainda na década de 1960, este consumo desenfreado de bens, fez com que emergissem movimentos lastreados no ideal ecológico. No dizer de Guattari "o planeta Terra vive um período de intensas transformações técnico-científicas, em contrapartida das quais engendram-se fenômenos de desequilíbrios ecológicos que, se não forem remediados, ameaçam a vida em sua superfície" (1990, p. 07).

Acompanhando os movimentos mundiais acerca das questões ambientais, em especial a ideia de que "o futuro da humanidade inclui, obviamente, o futuro da natureza como sua condição sine qua non" (JONAS, 2006, p. 229), a Constituição brasileira, de 1988, traçou uma almejada harmonia entre o consumo e a preservação. Essa proposta lhe trouxe a denominação de "Constituição verde". Além de receber essa nova denominação, atribuída por alguns estudiosos, também fez surgir novos direitos, quando em seu texto expressou que é dever do Estado e de todos os jurisdicionados preservar o meio ambiente para as futuras gerações, tipificando os direitos conhecidos como difusos.

Embora a Constituição tenha estendido sua tutela ao bem jurídico ambiental, a atenção específica aos problemas dessa natureza nem sempre foi concretizadas pela prática da sociedade brasileira. Diante dessa atual conjuntura, cumpre refletir se a sustentabilidade é compreendida como prática cotidiana e obrigatória, frente à larga escala de degradação ambiental que se acelera constantemente, uma vez que se vive uma nova era, repleta de crises e oportunidades.

Cumpre referir que é circular a evolução nesse âmbito, eis que se apenas houver a crise, os problemas, sem perspectiva de soluções, melhoras e evoluções, estar-se-á preso à inércia do não agir. Visualiza-se a dependência retrocitada, pois a capacidade de adaptação está intimamente ligada a de superação, ou seja, criar oportunidade de melhoras, soluções que até o momento de ter a "crise" não eram pensadas ou discutidas. Caso não houvesse as degradações ambientais, não seria necessária a mudança de hábitos, pensamentos e comportamentos para a sua preservação. A crescente degradação dos recursos naturais e o aquecimento global, ao mesmo tempo em que trazem enormes perigos à civilização humana, proporcionam oportunidades de erigir uma nova cultura de sustentabilidade em que se procura conciliar o desenvolvimento econômico e responsabilidade social e ambiental.

Para possíveis soluções à questão ambiental, devem-se buscar soluções duradouras, pensando a médio/longo prazos, com o desenvolvimento de estratégias que se estendam por escalas temporais, de modo que as escolhas políticas, hoje adotadas, afetarão a vida das futuras gerações. Portanto, é preciso um pensar/agir que ultrapasse gerações, a fim de garantir a qualidade e a existência, não só das atuais, mas das futuras, posto que haja um dever individual dos seres, para obter um bem estar coletivo. Nessa óptica, saber lidar com o desconto do futuro é obrigatório para os defensores do paradigma da sustentabilidade, pois cresce, assim, a responsabilidade, especialmente dos mais ricos e dotados, embora cada ser humano seja chamado, de modo proporcional, a se afastar da cumplicidade com a marcha do lapso. Quem nada fizer será solidariamente responsável (PEREIRA; CALGARO, PEREIRA, 2011).

Por conseguinte, faz-se necessário chamar a atenção do consumidor-cidadão para o seu comprometimento com escolhas sustentáveis e inserir-se na observação do ordenamento constitucional em prol de práticas ambientalmente sadias. Faz-se necessário uma intervenção rápida e forte do ente estatal para formar este laço necessário, e assim quebrar a resistência cultural de que à sociedade civil cabem tão somente exigências, sem deveres.

Diante do já referido quadro de desenfreado consumo, cria-se o binômio consumidor-ofertador. Dado ao fato de que o primeiro demandante é reconhecido como mais vulnerável na relação e que o 
segundo demandante detenha o domínio da situação, criou-se um sistema protetivo àquele, incluindo o dever de prestar todas as informações necessárias sobre o produto/bem adquirido, de modo a garantir a sadia qualidade de vida. Todavia, a necessária leitura hermenêutica do texto constitucional promove o casamento da seara consumerista e da promoção do meio ambiente sadio. Se, de um lado, tem-se a obrigação de informar as especificidades do produto ofertado, garantindo assim a segurança e a saúde do consumidor, de outro lado tem-se o dever do consumidor em utilizar-se do seu direito à informação, na busca de produtos que sejam ecologicamente corretos para, deste modo, garantir a sadia qualidade de vida e a promoção de um meio ambiente igualmente sadio.

Destaca-se que esta interpretação ainda é realizada de forma fragmentada: o consumidor, basicamente, preocupa-se com a rotulagem dos produtos, a proibição da publicidade dolosa, a fixação da responsabilidade do produtor e do vendedor, ficando assim comprometido um olhar mais atento às questões ambientais (BRASIL, 2013). Nesse passo, o Código de Defesa do Consumidor consagra como princípios basilares das relações de consumo: o princípio da vulnerabilidade (artigo 4⿳⺈, inciso I), o princípio da informação e da educação (artigo $4^{\circ}$, inciso IV), o princípio da segurança e qualidade (artigo $4^{\circ}$, inciso $\mathrm{V}$ ), dentre outros.

O que se quer com isso é preservar o lado mais vulnerável da relação de consumo. O diploma consumerista promove a proteção do agente que impulsiona e movimenta a economia, estabelecendo a responsabilidade do fornecedor, principalmente no que diz respeito às informações sobre o produto. Nesse contexto, o direito à informação torna-se vetor primordial de escolha para o consumidor, no que tange aos riscos que se expõe conscientemente. Nessa perspectiva, o direito à informação corresponde fundamentalmente ao dever da empresa de levar ao conhecimento dos potenciais consumidores com lealdade e veracidade, as indicações necessárias a uma escolha criteriosa, empregando meios diversos, sobretudo a publicidade comercial.

$\mathrm{O}$ direito à informação corresponde à necessidade de se esclarecer o consumidor sobre as possibilidades e os riscos, para que ele possa exercer livre e conscientemente seu direito de escolha em relação ao tipo de produto a ser consumido (ENGELMANN, 2012). O consumidor tem o direito de conhecer todos os riscos reais e potenciais, para decidir sobre a utilização do produto, assumindo as consequências da sua escolha. Desse modo, será possível a escolha comprometida com a sua qualidade de vida e a qualidade de vida das futuras gerações, nos termos constitucionais de proteção, preservação e cuidado ambiental.

Dentre os princípios retrocitados, percebe-se que o binômio consumidor-ofertador se alicerça em uma relação de vulnerabilidade, associando-se a esta ideia o princípio da informação e qualidade. Eis que é dever do ofertador não só fornecer informações sobre o produto, mas garantir a qualidade do mesmo. Encontra-se intrínseco ao direito da informação, o princípio da responsabilidade ética que deve ser exercido tanto pelos consumidores quanto pelos fornecedores.

No tocante a ética, observa-se a necessidade do comprometimento com uma nova postura de agir e pensar, de maneira a desenvolver hábitos mais responsáveis, bem como ecologicamente corretos. Nesse sentido, Jonas afirma que certas transformações em nossas capacidades acarretaram "uma mudança na natureza do agir humano. E, já que a ética tem a ver com o agir, a consequência lógica disso é que a natureza modificada do agir do humano também impõe uma modificação na ética" (2006, p. 29). Assim, ao direito de escolha se junta a responsabilidade de se consumir produtos que sejam ecologicamente sustentáveis, pois na medida que os consumidores exercerem seu direito de escolha consciente, tecem uma cadeia de responsabilidade, desde o produtor até o seu destino-fim que é o próprio consumidor. Em outros termos, ao se proteger o ambiente ecologicamente equilibrado, também se resguarda a vida e a saúde humanas (MAIA, 2012, p.198).

A responsabilidade ética ultrapassa a obediência estrita da lei; imprime-se um comprometimento moral tanto dos que ofertam produtos e serviços quanto dos consumidores, configurando a mútua responsabilidade a ser exercida. Cria-se, assim, uma relação de direito-dever, pois enquanto um lado do binômio (consumidor-ofertador) tem a obrigação de fornecer informação acerca do produto ofertado, é dever o consumidor prezar pelo produto que traga melhor qualidade à sua saúde. Ainda a esse respeito, acrescenta-se que há direitos que devem ser exercidos pelo cidadão-consumidor, principalmente no que se refere à vigilância no processo de produção, asseverando que não podemos 
entender um consumidor passivo, não participante, pequeno e indefeso diante das forças de produção e da distribuição, sem capacidade de ação e reação (MIRAGEM, 2012).

Enfim, o que se quer é produzir uma quebra de paradigmas viciosos, uma ruptura com relação às posturas de irresponsabilidade perante o meio ambiente, tendo em vista uma nova postura ética. Produzir uma nova cultura, em que o consumidor possa assumir um papel ativo e responsável na sociedade, ou seja, desenvolver atitudes de agente fiscalizador, deixar de ser o coadjuvante e se tornar protagonista da mudança social. Agindo assim será respeitado pelos produtores e não lhes deixará opção a não ser se adequar as normas ambientais.

\section{Meio ambiente sadio: princípio do cuidado na produção de alimentos vegetais}

Consta-se que a sociedade contemporânea se encontra descompromissada com as consequências do desenvolvimento não ecológico, isso por que se encanta com as novas tecnologias sem pensar no impacto ambiental. Vale destacar que, alimentos de origem vegetal podem ocasionar grandes perigos, tanto para a saúde humana quanto para a natureza. A humanidade sempre demonstrou fascínio pelo novo, pelo desconhecido, o que vem a potencializar a característica mais marcante da contemporaneidade, a conhecida "sociedade de risco", uma vez que o "encantamento pré-genético" que a humanidade tem pelo novo, somado ao veloz desenvolvimento tecnológico, caracteriza o momento degradante que se encontra o meio ambiente (DUPAS, 2006).

A "sociedade de risco" pode ser denominada também de "sociedade sofrível". Porquanto, tem-se sofrido com as próprias atitudes, muito embora se tenha conhecimento da importância de se ter uma qualidade de vida saudável, o "encantamento" pelo novo, cega o conhecimento dos riscos que assume e dos danos que são causando ao meio ambiente. Entretanto, esses danos ultrapassam barreiras territoriais, passando a serem riscos globais, planetários, ameaçando visivelmente a existência da vida humana e de todas as demais espécies na terra. Apropriado, nesse momento, é o ensinamento de Engelmann e Machado:

(...) os riscos na Sociedade Industrial caracterizavam-se por sua 'previsibilidade e limitação espacial, uma vez que sua amplitude era restrita em função da dimensão do dano que poderia advir de uma atividade localizada em determinado espaço físico do globo e afetando, assim, determinada comunidade ou classe social. Por outro lado, na Sociedade de Risco, essa limitação espacial e social, perfeitamente determinável, dá lugar a uma dimensão globalizada que afeta todos indistintamente, até aqueles que os produzem (...) (2013, p. 20).

Os riscos que se manifestam ultrapassam barreiras e rompem com a ideia de problema individual e/ou isolado e passam a ser uma preocupação de ordem global. Na sociedade contemporânea, na qual a complexidade está em processo crescente, constata-se uma potencialização dos riscos decorrentes do rápido e sofisticado desenvolvimento tecnocientífico. Assim, torna-se palpável o grande desafio e a necessidade da intervenção do ente Estatal, no sentido de equilibrar o desenvolvimento tecnológico e econômico com ecológico, a fim de contemplar a norma constitucional.

O maior desafio do direito contemporâneo consiste em superar os hábitos viciosos e implementar uma nova ética, baseada no princípio responsabilidade, para assim assegurar, de acordo com os preceitos constitucionais a preservação do meio ambiente para as atuais e futuras gerações (LEITE; AYALA, 2011). Nesse sentido, faz-se necessário a efetivação do controle no que tange a produção de alimentos de origem vegetal. Notadamente, vive-se um contínuo afrontamento à ordem constitucional, principalmente, por que está se ferindo, em escala constante, um direito difuso que na sua essência tutela a qualidade de vida humana e, consequentemente, o princípio da dignidade da pessoa humana. Porém, não se pode deixar que o princípio basilar do Estado Democrático de Direito seja ferido e, segundo Engelmann e Machado, colocado em risco o:

direito fundamental do homem do presente e do futuro, o direito ao meio ambiente equilibrado, como condição à qualidade de vida, cabendo a todos (Poder Público e comunidade global) a defesa e preservação dessa garantia, conforme preceitua o art. 225 da CF/88, que assegura a "todos" (e "todas") o direito subjetivo de viver e conviver com o meio ambiente ecologicamente equilibrado (2013, p.15). 
O que, aqui, está em questão não é apenas o direito ambiental, mas o direito do consumidor, pois ambos estão diretamente correlacionados, assim "a degradação ambiental pode prejudicar ou comprometer o consumo humano de determinados bens (por exemplo, a poluição das águas, o uso de agrotóxicos e seus efeitos sobre produtos agrícolas, fauna e flora)" (MIRAGEM, 2012, p.74). Nesse âmbito, o Código de Defesa do Consumidor dispõe sobre a relação de produtos e meio ambiente estarem em harmonia. Para Miragem:

As normas de proteção do consumir, se relacionam mediatamente com a proteção do meio ambiente quando
consagram, dentre outros: (a) o direito básico a vida, saúde e segurança contra riscos de produtos perigosos e
nocivos (art.6,I, do CDC; (b) a efetiva prevenção de danos (art. 6,VI, do CDC); (c) a proibição expressa ao
fornecedor que coloque no mercado de consumo, produto ou serviço que sabe ou deveria saber apresentar alto
grau de nocividade ou periculosidade à saúde ou segurança (art.10 do CDC); (d) a proibição da publicidade que
desrespeita valores ambientais, porque abusiva (art.37, § 2, do CDC; (e) a qualificação como prática abusiva, e
consequentemente proibição, da colocação no mercado de consumo de qualquer produto ou serviço em
desacordo com as normas expedidas pelos órgãos oficiais competentes ou expedidas pela Associação Brasileira
de Normas Técnicas ou noutra entidade credenciada pelo Conselho Nacional de Metrologia, Normalização e
Qualidade Industrial (Conmetro); (f) a definição como abusiva da cláusula contratual que infrinja ou possibilite
a violação de normas ambientais (2012, p.75).

Observa-se que a Carta Magna, de 1988, em seu artigo 225, enfatiza como bem jurídico tutelado a sadia qualidade de vida, com isso protege diretamente a saúde dos indivíduos, ou seja, garante a segurança dos alimentos de origem vegetal. Entretanto, a nocividade poderá estar implícita, posto que o uso de produtos ambientalmente incorretos, além de lesar o meio ambiente, atinge diretamente o cidadão que o consumir. Nessa batalha vital, em prol da proteção ambiental e efetivação da norma positivada, faz-se necessário utilizar-se do Princípio da Precaução, que pode ser aplicado, em virtude de sua característica interdisciplinar, de forma efetiva a todos os "níveis" de desenvolvimento, visando garantir a qualidade de vida. Segundo Engelmann e Machado "é exatamente nesse panorama de incertezas, inseguranças e novidades que se sedimenta o Princípio da Precaução, com missão de manter uma vida sustentável no planeta" (2013, p.15).

Atualmente, destaca-se a preocupação com os alimentos de origem vegetal, uma vez que estão relacionados diretamente com o meio ambiente. Ora, torna-se imperioso a aplicação do Princípio da Precaução, para nortear todo o processo de desenvolvimento, garantindo que os alimentos de origem vegetal tenham qualidade, pois a proteção da saúde e segurança do consumidor consiste em medidas que o Estado deve adotar para a proteção física dos consumidores contra o uso de produtos defeituosos ou perigosos, principalmente os alimentos (BENJAMIN; MARQUES; BRESSA, 2010).

A referência ao princípio da Precaução está voltada para que o foco da ciência e da tecnologia seja colocado a favor a qualidade de vida humana e extra-humana. $\mathrm{O}$ agir sob a perspectiva da Precaução visa evitar futuros danos que poderão ser irreversíveis, principalmente, em relação ao consumo de alimentos de origem vegetal que trazem riscos invisíveis. Pertinente a isso é o desenvolvimento sustentável, tal como mencionado na Constituição Federal, cuja responsabilidade ética do cientista é desenvolver tecnologias sem esgotar os recursos naturais e ter o real comprometimento com a sadia qualidade de vida. O desenvolvimento científico se processa nas mais diversas esferas, inclusive no que tange a melhorar a qualidade de vida das pessoas. Entretanto, as tecnologias utilizadas para que esse objetivo seja alcançado deparam-se, atualmente, com um novo desafio: não diminuir o ritmo de desenvolvimento se esgotar os recursos naturais disponíveis no planeta, deixando para as futuras gerações condições de sobrevivência. É o que denomina desenvolvimento sustentável (BRÜSEKE, 2003).

Diante de tanto desenvolvimento tecnológico, faz-se necessário também desenvolver alimentos vegetais sadios que não agridam o meio ambiente na sua produção e garantam a preservação da saúde do consumir. Trata-se de estabelecer uma relação de responsabilidade ética entre os produtores e os consumidores, em que cabe aos produtores observar com as normas ambientais e aos consumidores usufruir de alimentos que preservem a sadia qualidade do meio ambiente. Desse modo, há um compromisso mútuo, pois a preservação dos recursos naturais pode ser definida com um compromisso moral que temos com as futuras gerações (JONAS, 2006). 
Dessa forma, verifica-se que o Estado Democrático de Direito não pode estar alheio às discussões no que tange a segurança alimentar. Além desse compromisso mútuo é necessário, também, que se tenha a efetivação de políticas públicas que controlem todo o processo de produção dos alimentos, desde a fertilização e manutenção do solo, os tipos de agrotóxicos usados, até seu destino final, ou seja, o consumidor.

\section{Informação do consumidor e compromisso ambiental: a rastreabilidade de alimentos e o estado democrático de direito}

A ideia de sustentabilidade está vinculada à ideia de progresso ecologicamente correto (FREITAS, 2011). A humanidade espera que a ciência apresente uma solução milagrosa aos problemas ambientais, descartando completamente a chance de controle e efetivação da proteção ambiental que se concentra em suas mãos. Acredita-se, erroneamente, que a sua atitude diária de exercer o direito à informação é pequeno, diante de infinitas oportunidades de consumo que mascaram as informações. Desse modo, haverá escolhas equivocadas e inadequadas à qualidade de vida, comprometendo a preservação do meio ambiental, não só contemporaneamente, mas para as futuras gerações, descumprindo o estipulado pela Constituição Federal.

O que se quer não é só um progresso ecologicamente correto, mas anseia-se, sobretudo, por um progresso ético, comprometido com a problemática ambiental e não somente com desenvolvimento tecnológico. Tendo como objetivo principal, a ética alicerçada nos valores de preservação ao ambiente, Hans Jonas afirma que "como já tivemos de aprender, há um preço que se paga por esse progresso: como cada ganho também se perde algo valioso. Não é necessário lembrar que o custo humano e animal da civilização são altos e, com o progresso, tende a aumentar"' (2006, p.269).

Porquanto, não há mais como admitir um progresso sem rumo, que acarreta em imensa perda de patrimônio ambiental (DUPAS, 2006). A cegueira pelo econômico faz com que a preservação do meio ambiente se torne imperceptível, diante da gigantesca máquina capitalista. Logo, faz-se necessário uma concepção ética comprometida com o cuidado, que irá guiar para onde se quer ir e como chegar sem devastar o meio ambiente. Assim, teremos dois distintos e interligados momentos: distintos, por que são posturas que devem ser tomadas por diferentes agentes, e, interligados, por que juntos formarão um ciclo que tem o mesmo objetivo a ser atingido, qual seja, a preservação do meio ambiente.

O primeiro momento envolve o direito da sociedade em ter acesso a informações sobre o produto que está consumindo. Ou seja, se o produtor está cumprindo as normas ambientais, se visa não somente o econômico, mas se coloca à disposição do consumidor produtos de qualidade que não prejudiquem o meio ambiente e a qualidade de vida de quem os consome. Constitui-se, também, um dever da sociedade não consumir alimentos cujos fornecedores/produtores não estejam cumprindo com as normas ambientais. Essa atitude excluirá do mercado àqueles produtores que forneçam alimentos nocivos à saúde humana e que comprometem o meio ambiente.

O segundo momento constitui dever do Estado, fiscalizar a produção dos alimentos de origem vegetal, pois cabe a ele primar pelo bem-estar da sociedade. O ente Estatal tem o dever de pensar no desenvolvimento coletivo e ser o impulsionador de um progresso sustentável, "a importância econômica e a onipresença dos alimentos na nossa vida implicam que a segurança dos alimentos dever ser um dos principais interesses da sociedade em geral e, em particular, das autoridades públicas e dos produtores" (UNIÃO EUROPÉIA, 2000, p. 04). Para tanto, faz-se necessário que o Estado institua Políticas Públicas que controlem toda cadeia de produção de alimentos, para assegurar e garantir a observação das normas ambientais de preservação. Esse processo é "motivado pela necessidade de garantir um nível elevado de segurança dos alimentos" (UNIÃO EUROPÉIA, 2000, p.02). Ou seja, o Estado precisa pensar em instituir a rastreabilidade dos alimentos, enquanto procedimento que permite seguir e localizar os produtos, desde a sua matéria-prima, produção, comercialização, mediante registro, identificação e transmissão de informação. A possibilidade de identificação de elementos nocivos pode ocorrer em qualquer etapa da cadeia alimentar, por isso a rastreabilidade torna-se instrumento indispensável para garantir a qualidade alimentar. 
Ante o fenômeno da globalização e da livre comercialização de produtos de gêneros alimentícios, torna-se difícil identificar a origem e as circunstâncias ambientais em que se desenvolvem os alimentos de origem vegetal. A fim de se assegurar um nível elevado de proteção e qualidade, quando detectar algum alimento que exponha o consumidor a nocividade, ficará fácil identificar o elemento causador e imediatamente sanar o problema. Por isso é de suma importância que os consumidores tenham clareza das informações acerca da origem e do cultivo desse alimento. Portanto, com a efetivação da rastreabilidade se permitirá que haja um padrão de qualidade nos alimentos orgânicos, ou seja, permitirá que "a produção e o consumo de alimentos é fundamental em qualquer sociedade e tem consequências econômicas, sociais e, em muitos casos, ambientais" (UNIÃO EUROPÉIA, 2000, p. 04).

A proposta da rastreabilidade dos alimentos visa proteger a saúde do consumidor e efetivar a proteção do meio ambiente para as futuras gerações. O objetivo principal desse mecanismo é a proteção à vida, pois o consumo de determinado alimento, mesmo não agredindo diretamente a saúde dos humanos, poderá degradar e impactar o meio ambiente, fonte essencial de vida dos humanos. Quanto à proteção a saúde dos consumidores e ambiental, a União Européia dispõe que:

Embora a proteção da saúde seja sempre prioritária, estas questões devem igualmente ser tomadas em consideração no âmbito da política alimentar. Além do mais, o estado e a qualidade do ambiente, designadamente dos ecossistemas, podem afetar diversas fases da cadeia alimentar. A política ambiental desempenha, pois, um papel importante quando se trata de garantir ao consumidor a segurança dos alimentos (2000, p. 04).

A proposta da rastreabilidade implica em uma política de segurança, que permita a avaliação e o controle dos riscos trazidos por alimentos de origem vegetal. Assim, se terá um sistema de controle, destinado a supervisionar e assegurar o cumprimento da legislação, isto é, um sistema que irá gerir toda a cadeia de produção alimentar. No entanto, o objetivo maior da rastreabilidade é criar uma mudança de hábito no mercado interno, gerar a participação atuante da sociedade para não consumir produtos que não estejam de acordo ou possuem segurança. Cabe ao Estado elevar o nível de transparência, ou seja, tornar público relatórios de inspeção, para proporcionar aos consumidores a oportunidade de realizar "boicotes" nos alimentos que de alguma maneira venham a agredir a saúde e o meio ambiente. Desse modo, a sociedade forçará os produtores, que quiseram se manter no mercado, a se adequarem, tendo em vista que a variedade disponível é vasta. Essa atitude consciente e critica implicará que somente os produtos ambientalmente corretos permanecerão no mercado. Os consumidores tem o direito de obter informações sobre os alimentos de origem vegetal, para escolherem somente aqueles que estão de acordo com a legislação (BRASIL, 2013).

Está se tornando habitual o relato de cidadãos, que encontram certas mercadorias com qualidade abaixo do exigível. Por exemplo: um consumidor, ao adquirir e abrir determinado produto de uma famosa marca de chocolate constata-se que esse produto encontra-se mofado. Porém, o chocolate tem sua matéria-prima no cacau, logo, de origem vegetal, no entanto sem a rastreabilidade não se pode detectar com precisão onde ocorreu a falha. Eis o motivo para alguns questionamentos, tais como: em que momento isso ocorreu? O problema está na falta de qualidade do cacau fornecido? Foi erro na produção? Foi armazenado de maneira errada? Quantos produtos apresentaram esse problema? Com a implantação da rastreabilidade se conseguirá, com maior precisão e rapidez, responder a esses questionamentos, bem como exigir que não somente o produtor de cacau esteja de acordo com as normas ambientais, mas também que a fornecedora do produto final esteja cumprindo com as regras ambientais.

Diante do exposto, identifica-se uma cadeia de elementos interligados que orientados corretamente podem fazer cumprir o determinado na Constituição Federal. Com isso, não somente a sociedade precisa de informação, mas no caso em tela, a marca famosa de chocolate também, uma vez que seu nome ligado a um produtor que não obedece às normas ambientais, também será alvo do "boicote" da sociedade. Esse procedimento não somente trará segurança ao consumir produtos orgânicos, mas também promoverá, de forma efetiva, que os cidadãos cuidem do patrimônio global (CERQUEIRA; REIS, 2011). 


\section{A rastreabilidade dos alimentos como política pública de fomento aos direitos consumeristas e ambientais}

O Estado contemporâneo tem como atribuição garantir não só uma qualidade de vida melhor a seus jurisdicionados, mas também às futuras gerações um meio ambiente saudável. Assim, a qualidade de vida e a proteção ambiental deixam de ser uma questão de ordem individual e passa a ser global. É preciso atentar-se para os problemas ambientais de forma ampla, contextualizada e principalmente contemporânea. Os problemas como desmatamento e queimadas, não são os únicos meios de agressão em massa ao meio ambiente, pois em uma era que a tecnologia é constantemente "atualizada", novos e inovadores são os modos de se agredir a natureza. Sobretudo, quando "a humanidade sempre demonstrou um fascínio pelo novo, pelo desconhecido" (ENGELMANN; MACHADO, 2013, p. 14).

Assim, faz-se necessário que o Estado Democrático de Direito institua uma política pública para efetivar e garantir a qualidade de vida e a preservação do meio ambiente. Rodrigues leciona que "política pública é o processo pelo qual os diversos grupos que compõem a sociedade- cujos interesses, valores e objetivos são divergentes - tomam decisões coletivas, que condicionam o conjunto dessa sociedade" (2010, p.13). À preservação do bem coletivo, torna-se necessário a implementação da rastreabilidade, como fonte de efetivação dos direitos dos consumidores e ambientais. Com este mecanismo de controle se possibilitará a concretização de tais direitos, bem como poderá se elevar a qualidade de vida dos cidadãos, de modo que "o processo de decisão em vigor assegura um grau elevado de responsabilidade e transparência, que poderia ser difícil de reproduzir numa estrutura descentralizada" (UNIÃO EUROPÉIA, 2000, p. 17).

A Comissão Europeia constatou a necessidade de garantir um elevado nível de segurança alimentar. Para tal, publicou no ano 2000, o Livro Branco, que enfatiza e traz à discussão uma série de regulamentações. A Comissão, em um primeiro momento, cria uma Autoridade Alimentar Européia, cujo objetivo é desenvolver o processo de rastreabilidade. A intenção da Comissão Europeia não é somente garantir a qualidade dos alimentos, mas elevar a proteção dos consumidores, para que assim "permita-se restabelecer e manter a confiança dos consumidores, constitui prioridade fundamental" (UNIÃO EUROPÉIA, 2000, p. 16). Ou seja, o objetivo da Comissão é resgatar uma relação de confiança dos consumidores, incrédulos na aplicabilidade da legislação, e instaurar uma relação duradoura e flexível entre produtor/consumidor.

A Comissão propõe a esta Autoridade Alimentar, algumas competências, dentre elas, destaca-se: a avaliação e a gestão dos riscos. Quanto à avaliação de riscos, tem o objetivo de formulação de pareceres científicos e recolhimento de amostras e analises de informações. Na gestão de riscos, tem o objetivo de controlar e aplicar a legislação, a partir dos resultados trazidos pela avaliação dos riscos. A função de controle deve estar na gestão de riscos, para permitir um atuar com eficácia em favor dos consumidores e garantir que as recomendações de ação resultantes da avaliação de riscos sejam devidamente aplicadas.

Para resgatar a confiança dos consumidores, faz-se necessário que haja a comunicação entre a avaliação e a gestão de riscos. Nesse sentido, a União Européia dispõe que:

\footnotetext{
A comunicação dos riscos é fundamental para garantir que os consumidores sejam devidamente informados e para diminuir o risco de surgirem receios injustificados em matéria de segurança dos alimentos. Essa comunicação implica que os pareceres científicos sejam objetos de uma ampla e rápida divulgação, apenas sob reserva das exigências habituais de confidencialidade comercial quando aplicáveis. Além do mais, devem proporcionar-se aos consumidores informações facilmente acessíveis e compreensíveis relativas não só a esses pareceres, mas também a questões mais vastas no âmbito da proteção da sua saúde (2000, p. 5).
}

A avaliação e gestão de riscos devem se comunicar entre si, de modo que as informações trazidas por estes institutos complementem um ao outro e inspirem a confiabilidade aos consumidores. $\mathrm{O}$ principal objetivo de uma Autoridade Alimentar Europeia será o de "contribuir para o nível elevado de proteção da saúde dos consumidores no domínio da segurança dos alimentos, que permita 
restabelecer e manter a confiança dos consumidores" (UNIÃO EUROPÉIA, 2000, p. 17). Notadamente, a maior preocupação da Comissão é com a qualidade e segurança dos alimentos, para isso designou três princípios como básicos da Autoridade Alimentar: independência, excelência e transparência. Os princípios retrocitados versam, respectivamente, sobre um agir independente em prol da sociedade, a fim de garantir a confiabilidade, não estando sujeito a interesses industriais ou políticos; no âmbito da excelência, busca-se a condição de referência científica, tendo a respeitabilidade como alicerce; e, por fim, a transparência, fator fundamental na rastreabilidade, que inspirará a confiança dos consumidores, pois se constatará que se trata de uma Autoridade comprometida com o bem estar da coletividade.

No que toca, especificamente, aos alimentos de origem vegetal, a rastreabilidade além de criar uma ordem de proteção ambiental, também fará com que a almejada qualidade dos alimentos se eleve e diminua a sua potencialidade nociva à saúde humana. "Os produtos de origem animal e vegetal apresentam riscos intrínsecos, ligados à contaminação microbiológica e química" (UNIÃO EUROPÉIA, 2000, p. 25). A aplicabilidade da rastreabilidade se faz cada vez mais urgente, pois através desta ferramenta se permitirá que a sociedade efetive seu direito a informação e também seu dever de preservar o meio ambiente. No que tange a aplicabilidade das normas jurídicas é preciso uni-las para atingir o cumprimento dos objetivos: qualidade dos alimentos de origem vegetal e preservação do meio ambiente. Diante do exposto, pode-se verificar a importância da criação de uma Autoridade Alimentar. O exemplo Europeu permite constatar que a implementação deste procedimento, tornou possível efetivação da proteção ambiental e alimentar dos consumidores, forçando assim os produtores a se adequarem às normas estabelecidas.

A Constituição Federal de 1988, além de proteger o meio ambiente, impõe que é dever do Estado e da coletividade preservá-lo, de modo que a protetividade enaltecida por ela, equacione as condições necessárias para que a evolução tecnológica ocorra sem causar impactos devastadores ao meio ambiente. Notadamente, ao longo das últimas décadas "assistiu-se uma evolução notável, tanto nos métodos de produção e processamento dos alimentos como nos controles necessários para assegurar a observância de normas de segurança aceitáveis" (UNIÃO EUROPÉIA, 2000, p. 01). No entanto, há uma busca incessante, com contagem regressiva, para que se concretize a proposta de um meio ambiente sustentável e desenvolvimentos ecologicamente corretos. Para tanto, a rastreabilidade vem desempenhar o papel fundamental na aplicabilidade de forma eficaz da legislação ambiental e proteger de forma plena o direito a informação do consumidor.

Nesse contexto, a União Européia orienta que cabe à Comissão, em conjunto com a nova Autoridade Alimentar Europeia, promover:

\footnotetext{
Diálogo com os consumidores a fim de incentivar a sua participação na nova política de segurança dos alimentos. Ao mesmo tempo, é necessário assegurar uma melhor informação dos consumidores sobre os novos problemas de segurança dos alimentos e os riscos que determinados alimentos apresentam para certos grupos da população. Os consumidores têm o direito de esperar que lhes sejam fornecidas informações úteis e claras sobre a qualidade e os constituintes dos alimentos, por forma a poderem escolher com conhecimento de causa. Assim, serão apresentadas propostas em matéria de rotulagem dos alimentos, baseadas nas regras em vigor. A importância de uma alimentação equilibrada e o seu impacto sobre a saúde serão explicados aos consumidores (2000, p.02).
}

Desta forma, a fim de consolidar a nova política pública, a rastreabilidade visa assegurar que haja comunicação entre os produtores, fornecedores e consumidores. Neste norte, a União Européia dispõe que "a comunicação dos riscos é um intercâmbio entre as partes interessadas sobre a natureza dos riscos e as medidas adotadas para controlar" (2000, p.36). O dever de promover esta comunicação é do ente Estatal, no momento da inserção da rastreabilidade como política pública de fomento a efetivação de um Estado sustentável, constitui "uma responsabilidade fundamental das autoridades públicas no âmbito da gestão dos riscos para a saúde pública. Esta política constitui um elemento-chave da comunicação dos riscos e da confiança do público, pelo que deve ser ativamente prosseguida" (UNIÃO EUROPÉIA, 2000, p. 36).

O Estado objetiva que a sociedade desempenhe seu importante papel de exercer a proteção ambiental, porém é preciso que este promova uma mudança de hábitos, uma nova postura ética, que 
implique uma escolha de como se quer viver (VIOTTI, 2001). Assim, deverá fornecer aos cidadãos a oportunidade de realizar escolhas conscientes, através da transparência contida na rastreabilidade. Para se atingir a finalidade principal da Carta Magna, isto é, preservar o meio ambiente, sobretudo, em um contexto cujos avanços tecnológicos produzem impactos silentes e irreversíveis, faz-se necessário a implementação da rastreabilidade dos alimentos de origem vegetal.

O poder de fiscalizar e "punir" não estarão concentrados somente na figura do Estado, mas também sob a responsabilidade dos cidadãos que são os principais interessados na concretização desta política pública. Os grandes problemas contemporâneos envolvem saúde e meio ambiente: o primeiro grande problema refere-se diretamente ao segundo, pois a qualidade dos alimentos de origem vegetal depende única e exclusivamente da qualidade do meio ambiente em que é cultivado. A rastreabilidade aplicada e desenvolvida na Europa reserva-se a tratar de segurança alimentar, porém a Constituição Federal impõe o dever de preservar o meio ambiente. Logo, a rastreabilidade dos alimentos de origem vegetal irá proporcionar a concretização deste ideal constitucional.

A partir da implantação da rastreabilidade dos alimentos de origem vegetal, haverá um maior controle Estatal e Social dos produtores. Esse instrumento permitirá aos consumidores o acesso às informações, tais como: onde é cultivado o alimento, se está em conformidade com as normas ambientais, dentre outras. A transparência, contida na rastreabilidade, irá permitir que os consumidores tenham discernimento sobre os riscos contidos ou não nos alimentos e, consequentemente, poderão decidir livre e conscientemente no momento da sua aquisição.

Portanto, os benefícios trazidos pela rastreabilidade estão interligados entre si e tem eficácia duradoura, fundamentalmente no que tange ao meio ambiente. Pensando na qualidade dos alimentos, o cidadão consumirá preferencialmente produtos mais saudáveis e estará não só preservando a sua saúde, mas também protegendo o meio ambiente, já que alimentos saudáveis requerem meio ambiente saudável. Somente assim se efetivará de maneira duradoura, a proposta constitucional de se ter um Estado Democrático de Direito sustentável, servindo de exemplo global.

\section{Considerações finais}

Consumo e meio ambiente, conceitos que até o final do século XX eram vistos de forma dissociada, hoje devem ser compreendidos de maneira conjunta. Diante do problema da degradação ambiental, iniciou-se o discurso acerca das práticas sustentáveis. A Constituição Federal, no caso particular do Brasil, consagrou-se como Constituição verde por proteger o meio ambiente, uma vez que a existência da humanidade depende do comportamento e do pensar coletivo. Não obstante, a Constituição brasileira de 1988, além de assegurar o direito ao meio ambiente sadio, também preconiza a defesa dos direitos do consumidor. O presente texto discutiu a importância do consumidor, sobretudo, em tempos de novas tecnologias e de acesso ao conhecimento, para que se possa cumprir a sua tarefa ética-constitucional de, por meio da escolha livre e consciente, consumir alimentos e/ou produtos que respeitem as normas ambientais, desde o seu processo de produção até a entrega final.

O meio ambiente sustentável é compromisso também do consumidor-cidadão que, munido de seu direito à informação e por meio de suas escolhas, passa a ter o dever de zelar pela proteção ambiental. O sentido da palavra sustentabilidade é amplo e encaixa-se em todas as áreas, porquanto é a habilidade de suprir as necessidades básicas, sem desperdiçar e impactar o meio ambiente. Para tanto, exige-se a criação de uma nova postura ante a natureza, alicerçada em uma nova ética da responsabilidade, para assim garantir a coexistência pacífica e a sobrevivência da humanidade (presente e futura).

O desenvolvimento tecnológico e econômico não precisa ser resistente à sustentabilidade, basta que se busque um equilíbrio entre ambos. Trata-se de ter uma atuação conjunta entre Estado e os seus jurisdicionados, equacionando-se desenvolvimento e sustentabilidade. Somente assim será possível efetivar ações que perdurem e viabilizem a preservação da natureza. Contudo, verifica-se que o Estado está muito distante de efetivar uma política pública comprometida em inverter esse quadro degradante e sofrível, que vive o meio ambiente. 
A transição de uma cultura consumerista para uma mentalidade ecologicamente correta, exige por parte do Estado a criação de uma nova cadeia de cooperação entre os seus jurisdicionados. Caso não ocorram mudanças palpáveis e significativas, isto é, se o Estado não envolver e exigir comprometimento dos seus cidadãos, nas políticas propostas, será muito difícil a efetivação do normatizado pela Constituição Federal, no seu artigo 225, que estabelece como responsabilidade de todos zelar pelo meio ambiente saudável, inclusive para as gerações futuras.

Resta ainda salientar que um dos princípios regentes da ordem constitucional é o da dignidade da pessoa humana. Alicerçado neste princípio e no compromisso do Estado e da sociedade em proteger, defender, fiscalizar e preservar o meio ambiente, o consumidor-cidadão é chamado à prática de efetivação da norma constitucional. Um dos instrumentos fundamentais para a efetivação da norma constitucional é a inserção de práticas de sustentabilidade. O mercado é vasto em quantidade, ficando o dever do consumidor de escolher um produto que não traga malefícios a sua saúde, nem impactos degradantes ao meio ambiente (bem de uso comum de todos e das futuras gerações). Para tanto, faz-se necessário observar se o produto que se consume está em acordo com os dispositivos legais ambientais. Deste modo, o consumidor estará assegurando para si e para as próximas gerações, qualidade de vida e um meio ambiente equilibrado e sadio.

Para finalizar esse artigo, cumpre destacar que, infelizmente, ainda há no Brasil uma grande dificuldade para se implementar a efetivação de políticas públicas que promovam a preservação do meio ambiente e que priorizem o bem estar da sociedade. Mostra-se necessária, dessa forma, a observação dos projetos já propostos pela Constituição, a fim de se constatar a adequação dos mesmos para se efetivar a proteção tutelada pela Carta Magna. Nesse sentido, a rastreabilidade apresenta-se como um meio viável para a efetivação das propostas constitucionais.

\section{Referências}

BENJAMIN, A. H. V.; MARQUES, C. L.; BESSA, L. R. Manual de Direito do Consumidor. 3. ed. rev., atual. e ampl. São Paulo: Revista dos Tribunais, 2010.

BRASIL, Ministério do Meio Ambiente. Quem é o consumidor consciente. Disponível em < http://www.mma.gov.br/responsabilidade-socioambiental/producao-e-consumo-

sustentavel/consumo-consciente-de-embalagem/quem-e-o-consumidor-consciente $>$. Acesso em 04.jun.2013.

BRÜSEKE, F. J. O Problema do Desenvolvimento Sustentável. In: CAVALCANTI, Clóvis (org.). Desenvolvimento e Natureza: estudos para uma sociedade sustentável. 4 ed. São Paulo: Cortez, 2003, p. 29-40.

CAVALCANTI, C. Sustentabilidade da Economia: paradigmas alternativos de realização econômica. In: CAVALCANTI, C. (org.). Desenvolvimento e Natureza: estudos para uma sociedade sustentável. 4 ed. São Paulo: Cortez, 2003, p. 153-176.

CERQUEIRA, K. L; REIS, J. R. Educar para proteger: a importância da educação para o consumo em tempos de consumismo. In: REIS, J.R.; CERQUEIRA, K.L.; HERMANY, R. (orgs.). Educação para o Consumo. Curitiba: Multideia, 2011, p. 87-108.

UNIÃO EUROPÉIA. Livro Branco sobre a segurança dos alimentos. Comissão Européia: Bruxelas, 2000.

Disponível em <http://ec.europa.eu/dgs/health_consumer/library/pub/pub06_pt.pdf>

DUPAS, G. O mito do progresso. São Paulo: UNESP, 2006.

ENGELMANN, W. O direito à informação como um direito fundamental: os desafios humanos da comercialização de produtos elaborados a partir das nanotecnologias. In: BORTOLANZA, G.; BOFF, S. O. (Coord.) Direitos Fundamentais e Novas Tecnologias. Florianópolis: Conceito Editorial, 2012. 
ENGELMANN, W.; BERGER FILHO, A. G. As nanotecnologias e o direito ambiental: a mediação entre custos e benefícios na construção dos marcos regulatórios. Revista dos Tribunais, v. 15, n. 59, 2010.

ENGELMANN, W.; MACHADO, V. S. Do princípio da precaução à precaução como princípio: construindo as bases para as nanotecnologias compatíveis com o meio ambiente. Revista de Direito Ambiental. São Paulo: RT, v. 18, n. 69, 2013.

FREITAS, J. Sustentabilidade: direito ao futuro. Belo Horizonte: Fórum, 2011.

GUATTARI, F. As três ecologias. Campinas: Papirus, 1990.

JONAS, H. O princípio responsabilidade: ensaio de uma ética para a civilização tecnológica. Rio de Janeiro: Contraponto, PUC-Rio, 2006.

LEITE, J. R. M.; AYALA, P. A. Dano Ambiental: do individual ao coletivo extrapatrimonial. Teoria e prática. 4 ed. São Paulo: Revista dos Tribunais, 2011.

MAIA, M. C. O Direito à saúde à luz da Constituição e do Código de Defesa do Consumidor. Revista de Direito do Consumidor, ano 21, n. 84, p. 197-222, 2012.

MIRAGEM, B. Direito do consumidor e ordenação do mercado: o princípio da defesa do consumidor e sua aplicação na regulação da propriedade intelectual, livre concorrência e proteção ao meio ambiente. Revista de Direito do Consumidor, ano 21, n. 81, p. 39-88, 2012.

PEREIRA, A. O. K.; CALGARO, C.; PEREIRA, H. M. K. Educação e Políticas Públicas como Possibilidades de Criação de um Consumo Ambientalmente Sustentável. In: REIS, J. R.; CERQUEIRA, K. L.; HERMANY, R. (orgs.). Educação para o Consumo. Curitiba: Multideia, 2011, p. 27-46.

ROHDE, G. M. Mudanças de Paradigma e Desenvolvimento Sustentado. In: CAVALCANTI, C. (org.). Desenvolvimento e Natureza: estudos para uma sociedade sustentável. 4 ed. São Paulo: Cortez, 2003, p. 41-53.

VIOTTI, E. B. Ciência, Ética e Sustentabilidade. São Paulo: Editora Cortez 2001. 